\title{
Degradational response of engineered channels to changes in the upstream controls and channel width: Simplified 1D numerical simulations
}

\author{
Meles Siele ${ }^{1, *}$, Astrid Blom $^{1}$, and Enrica Viparelli $^{2}$ \\ ${ }^{1}$ Delft University of Technology, Faculty of Civil Engineering and Geosciences, Department of \\ Hydraulic Engineering, P.O. Box 5048, 2600 GA, Delft, the Netherlands \\ ${ }^{2}$ University of South Carolina, Department of Civil and Environmental Engineering, Columbia, USA
}

\begin{abstract}
In response to changes in the upstream controls (i.e., the water discharge, the sediment supply rate, and the calibre of the load), engineered alluvial channels adjust their bed slope and bed surface texture to establish a new equilibrium state. Here we present and discuss various causes of degradational response of engineered channels to changes in the upstream controls and channel width. For that purpose, we apply a simplified 1D numerical research code to a schematic river reach of constant width consisting of mixed-size sediment, and assess its equilibrium state and transient response. We illustrate that the following perturbation to an initially equilibrium state lead to a degradational response: an increase of the water discharge, a decrease of the sediment supply rate, an increase of the sand content of the sediment supply, an increase of the gravel content of the sediment supply, and a decrease of the channel width. Degradational response under all conditions is associated with surface coarsening. The equilibrium states of the numerical simulations agree with analytical solutions. The results provide insight into the current degradational response of engineered rivers, such as the Rhine River, the Elbe River and the Danube River.
\end{abstract}

\section{Introduction}

In response to changes in the upstream controls (i.e., the water discharge, the sediment supply rate, and the calibre of the load), engineered alluvial channels adjust to establish a new dynamic equilibrium (e.g. $[2,3]$ ). An engineered river is here defined as a channel with a fixed planform: it therefore responds to changes in controls through changes in channel bed slope and bed surface texture only rather than also through adjusting channel width. Worded differently, such adjustment (i.e., the transient phase) proceeds through changes in surface texture is set by the requirement of transporting the imposed sediment supply without aggradation and degradation (e.g. $[2,12])$. The equilibrium state can be disturbed

\footnotetext{
* Corresponding author: m.s.tewolde@,tudelft.nl
} 
by natural changes of the controls or by measures such as river training, repeated sediment dredging or augmentation. These disturbances induce an adjustment of the equilibrium state and the adjustment time scale required to establish the new equilibrium state following the changes in controls has been termed the relaxation time [5].

From an engineering point of view, knowledge and reliable prediction of the equilibrium state, the transient response and the associated adjustment time scale are essential to, for instance, mitigating problems associated with bed degradation. Relevant examples of degradational cases are the Rhine River, the Elbe River, and the Danube River, which are characterized by long-term trends of bed degradation [1, 14]. Fig. 1 illustrates the bed level change since 1934 in two branches of the Rhine River: the Bovenrijn (Rhine Km 858 to 867 ) and Bovenwaal (Rhine Km 868 to 885 ).
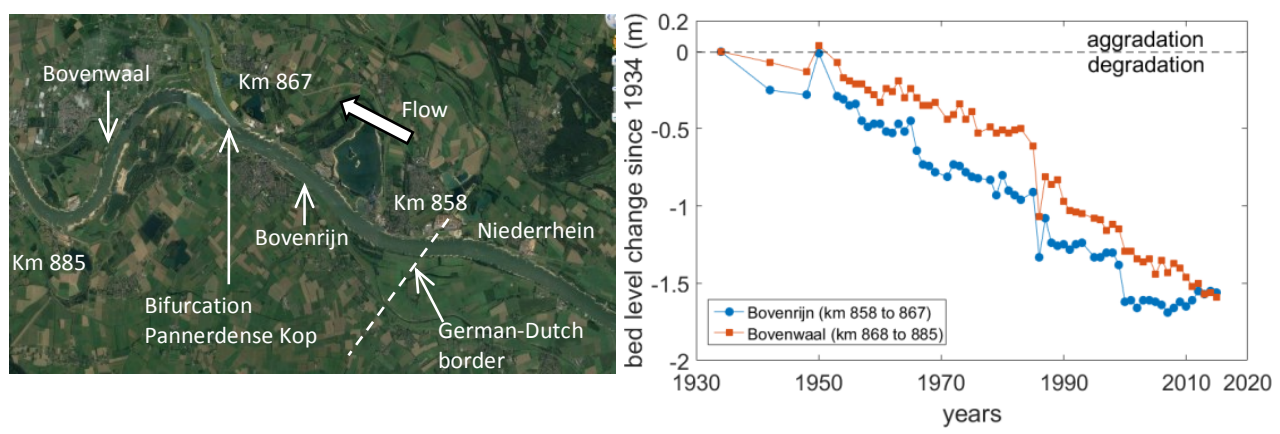

Fig. 1. Degradation in two branches of the Rhine River (right, Data source: Rijkswaterstaat), Plan view (left, source: Google earth)

This degradational response in the Rhine River leads to problems associated with navigation due to the presence of natural and man-made non-erodible layers, stability of structures, and ecology [1, 15]. The most important causes of the observed degradation (Fig. 1) are: the $19^{\text {th }}$ and $20^{\text {th }}$ century large-scale river training, extensive dredging in the past, sediment nourishment measures (where the added sediment is typically coarser than the bed sediment), and construction of dams in tributaries [1, 15].

In this study we use a numerical research code (Elv) [3, 4] to gain insight into the equilibrium state and the reasons of degradational response of engineered channels to changes in the upstream controls and channel width. Previous studies considering the transient state, e.g. $[5,6,13]$, have focused on the transient channel response in typically unisize sediment cases. Here, we extend these studies and assess the equilibrium state and transient degradational response regarding the channel slope and the bed surface texture in mixed-size sediment channels. To this end, we consider five types of perturbations leading to degradation of an initially equilibrium channel: (1) an increase of the water discharge; (2) a decrease of the sediment supply; (3) an increase of the sand content of the sediment supply; (4) an increase of the gravel content of the sediment supply; and (5) a decrease of the channel width. Finally, we assess the associated adjustment time scale and how it varies with changes in the controls and magnitude of the disturbance.

\section{Method}

We apply the numerical one-dimensional model Elv [3,4] to simulate the temporal and spatial change of channel slope, bed level, and bed surface texture. The model is applied to one dimensional schematic river $100 \mathrm{~km}$ long river reach consisting of two grain size fractions: gravel $\left(D_{50}=10 \mathrm{~mm}\right)$ and sand $\left(D_{50}=1 \mathrm{~mm}\right)$. The characteristics of the schematic 
reach is loosely based on the characteristics of the Waal River, which is a branch of the Dutch Rhine. We compute the flow solving the backwater equation and changes in bed level and bed surface texture by applying Hirano equations to conserve gravel and sand mass at the bed surface [14]. Bed load is computed with a fractional form of the MeyerPeter and Müller [7] bed load relation combined with the Egiazaroff [10] relation to account for hiding effects. We do not include the effects of abrasion, subsidence, uplift, sea level change and delta progradation. The initial state of each run is the equilibrium state associated with the initial value of the upstream controls and channel width.

Specifications of the initial state are: the channel length, $\mathrm{L}$ is $100 \mathrm{~km}$; the channel width, $\mathrm{B}$ is $300 \mathrm{~m}$; the bed slope equals $1 * 10^{-4}$; the water discharge is $1700 \mathrm{~m}^{3} / \mathrm{s}$; the supply rate of gravel equals $2.0 \mathrm{~m}^{3} / \mathrm{s}$; the supply rate of sand is $5.5 \mathrm{~m}^{3} / \mathrm{s}$; (i.e., the volume fraction content of the gravel in the supply is 0.26 ), the initial bed surface gravel content is 0.52 , the dimensionless friction coefficient, $\mathrm{c}_{\mathrm{f}}$ equals 0.007 , and the active layer thickness is $0.7 \mathrm{~m}$. The dimensionless friction coefficient and the active layer thickness are assumed to be constant. Initially the bed surface and substrate are assumed to have the same texture.

A perturbation is then introduced to one of the upstream controls or channel width: (1) $25 \%$ increase of the water discharge; (2) $50 \%$ decrease of the sediment supply, (3) $25 \%$ increase of the sand content in the sediment supply; (4) $25 \%$ increase of the gravel content in the sediment supply; and (5) 50\% decrease of channel width compared to its initial value.

\section{Results and discussion}

Here we present and discuss the equilibrium state and the transient response for the five cases introduced above. The initial and final equilibrium bed slope and bed surface texture agree with the results of the analytical models by Blom et al [3]. The equilibrium bed slope and surface texture are such that the flow velocity suffices to transport the supplied sediment downstream [12].

\subsection{Case 1: an increase of the water discharge}

When the water discharge to an equilibrium channel increases, the channel evolves towards a new equilibrium state that is characterized by a smaller bed slope without a change in the bed surface texture [2, 3], which is illustrated in Fig. 2A and 2B. As the rate and calibre of the sediment supply do not change, the flow velocity required to transport the load downstream does not change. This implies that the mobility difference between gravel and sand does not change and the surface texture in the new equilibrium state is the same as in the initial equilibrium state [2 3] (Fig. 2B).

In the transient state, the increase in water discharge increases the sediment transport capacity compared to the supply and hence a degradational wave (Fig. 2A) and a coarsening wave (and subsequently a fining wave) form and migrate downstream (Fig. 2B). This is shown by the arrows in Fig. 2A, B, which show the direction of change in the transient phase.

\subsection{Case 2: a decrease of the sediment supply}

When a mixed-size sediment channel is subject to a decrease in sediment supply (for instance due to construction of dams in tributaries), a smaller equilibrium bed slope and a coarser bed surface suffice to transport the decreased sediment flux downstream [2], which is illustrated in Fig. 2C and D. A smaller sediment supply requires a smaller equilibrium flow velocity to transport the sediment downstream and this reduced flow velocity increases the mobility difference between gravel and sand. The bed surface coarsens to 
compensate for this increased mobility difference by over-representing gravel at the bed surface (i.e., a mobile armor forms e.g. [8]). The over-representation of gravel at the bed surface acts to increase its availability and hence the gravel transport. The difference between the initial and the new equilibrium state induces a degradational adjustment through changes in bed slope and surface texture.

In the transient state, at the upstream end of the reach the sediment transport capacity is higher than the supply, which results in a downstream migrating degradational wave (Fig. 2C) and this wave is accompanied by a coarsening wave (Fig. 2D). The waves migrate downstream until a new equilibrium state is reached and the direction of migration of the waves is indicated by arrows in Fig $2 \mathrm{C}$ and 2D. These result confirms laboratory experiments by [16] and [17].
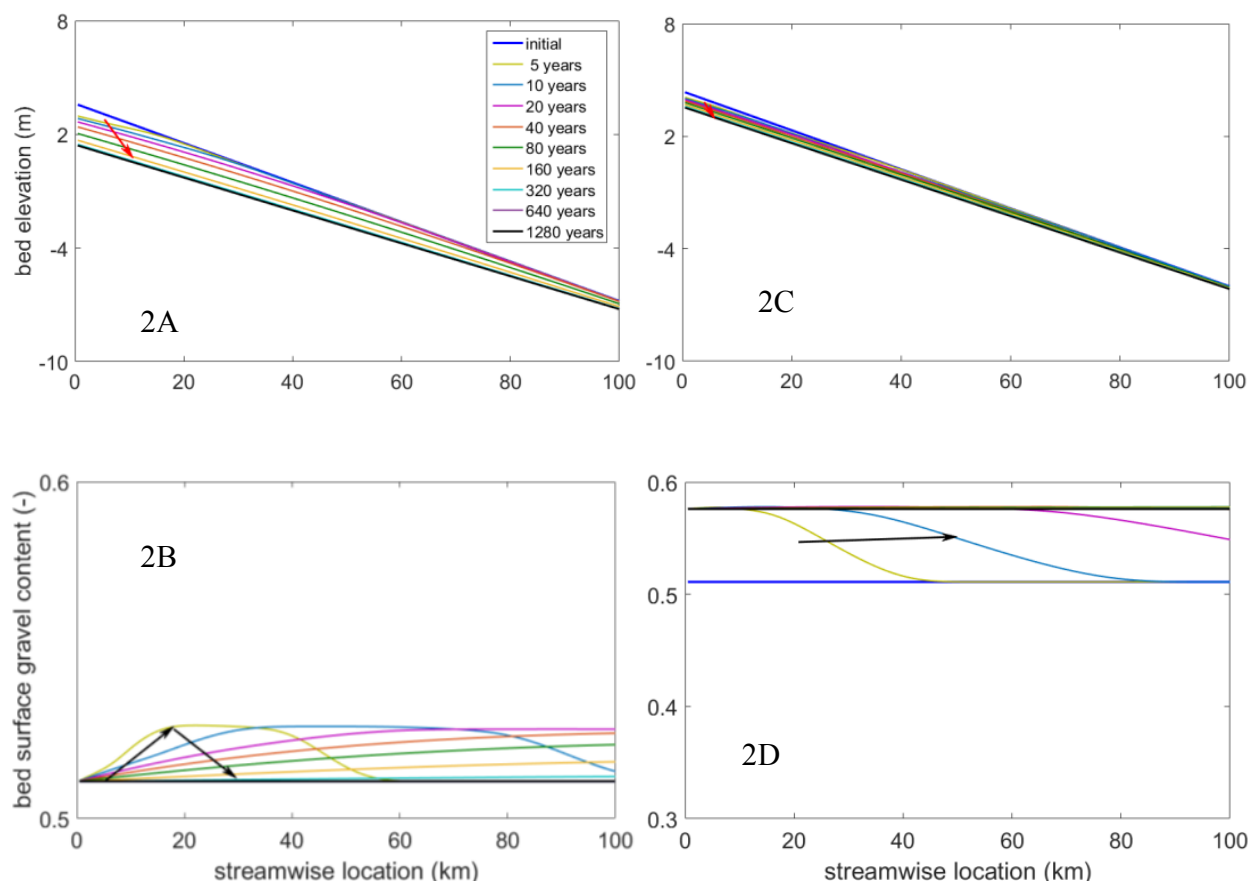

Fig. 2. Channel response to (2A, B) $25 \%$ increase of the water discharge (Case 1); and (2C, D) $50 \%$ decrease of the sediment supply (Case 2). Arrows show the direction of change in the transient phase

\subsection{Case 3: an increase of the sand content of the sediment supply}

When the sand content of the sediment supply increases, the new equilibrium state is characterized by a smaller slope and a finer bed surface (Fig. 3A, B) as a finer sediment flux requires a smaller slope and a finer surface to be transported downstream $[2,3]$. The fact that the new equilibrium state has a smaller slope and finer bed surface compared to the initial state leads to a transient state which is characterized by a degradational wave (Fig. 3A) and a fining wave that both migrate downstream (Fig. 3B).

Laboratory experiments have indicated this effect is even stronger when the increase of sand supply to a gravel bed channel increases the gravel mobility (e.g. [9, 11]). Such augmentation of fine sediment is becoming an increasingly popular restoration measure in armored gravel bed rivers (e.g. [9]). 


\subsection{Case 4: an increase of the gravel content of the sediment supply}

When the gravel content of the sediment supply to a mixed-size sediment channel is increased (for instance due to upstream coarse sediment nourishment), the new equilibrium state is characterized by a larger slope and a coarser bed surface, as these suffice to transport the coarser sediment downstream (Fig. 3C and 3D).

In the transient state, the coarsening of the sediment supply leads to an aggradational wave (Fig. 3C) and a coarsening wave that migrate downstream (Fig. 3D). Yet, the coarsening wave may induce a sediment deficit downstream of a coarsening wave and consequently, a preceding degradational wave forms and migrates downstream. As such the transient state is characterized by the downstream migration of coarse aggradational wave that is preceeded by a degradational wave, the latter of which can also be a coarsening wave. The direction of migration of the waves is indicated by arrows in Fig 3C and 3D.
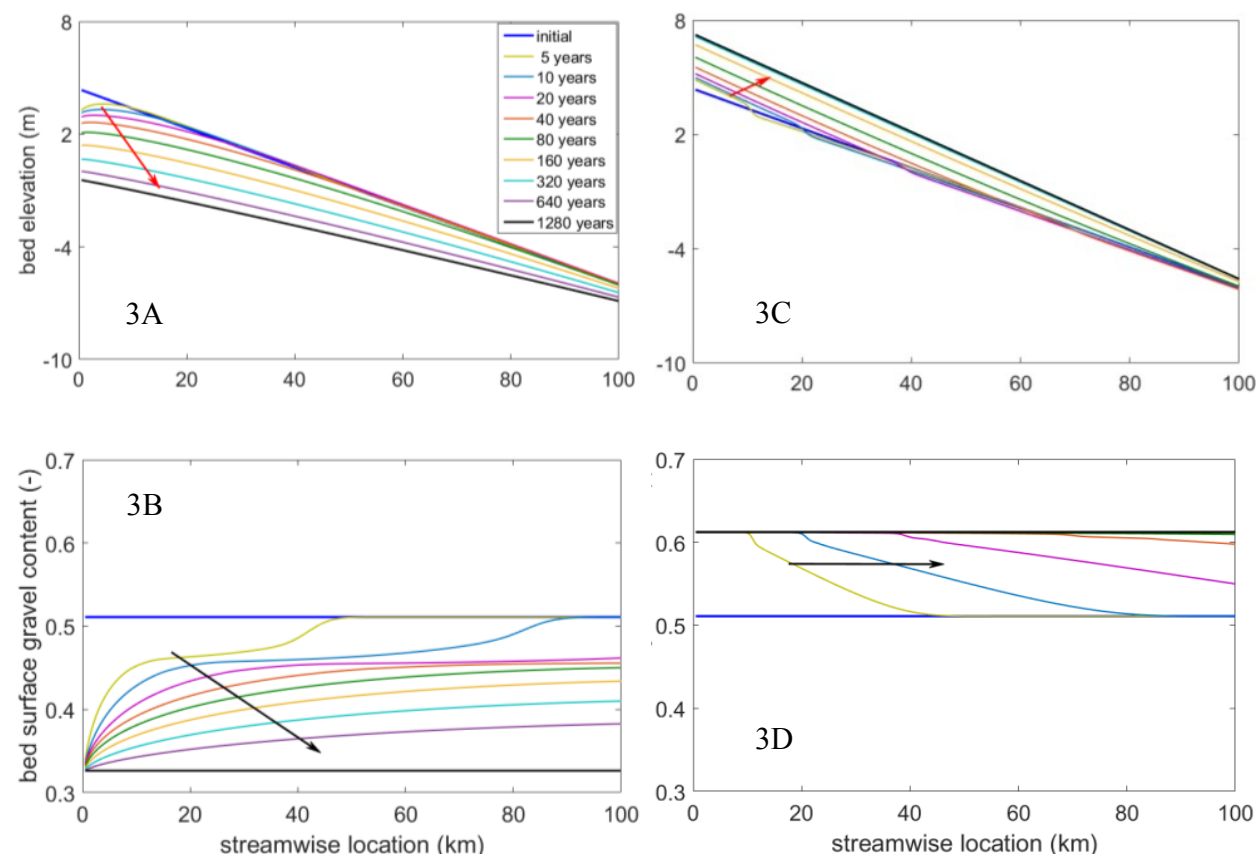

Fig. 3. Channel response to (3A, B) $25 \%$ increase in the sand content of the sediment supply (Case 3 ); and (3C, D) $25 \%$ increase in the gravel content of the sediment supply (Case 4). Arrows show the direction of change in the transient phase

\subsection{Case 5: a decrease of the channel width}

Here we impose a domain-wide decrease of the channel width. When a mixed-size sediment channel that is initially in equilibrium is narrowed (for instance, due to construction of levees and groynes), the specific water discharge increases and hence the channel attains a new equilibrium state that is characterized by a smaller bed slope and a finer bed surface (Fig. 4A, B). This is because narrowing leads to a higher sediment supply rate per unit width, which in the equilibrium state requires a higher flow velocity to transport the sediment flux downstream. This implies that the mobility difference between gravel and sand decreases, and the bed surface does not need to coarsen as much to transport the sediment flux downstream (Fig. 4B). In the transient state, the width reduction induces a degradational wave (Fig. 4A) as well as a fining wave (Fig. 4B) that migrate 
downstream until the new equilibrium is attained. The direction of change in the degradational wave and the fining wave is indicated by arrows in Figure below.
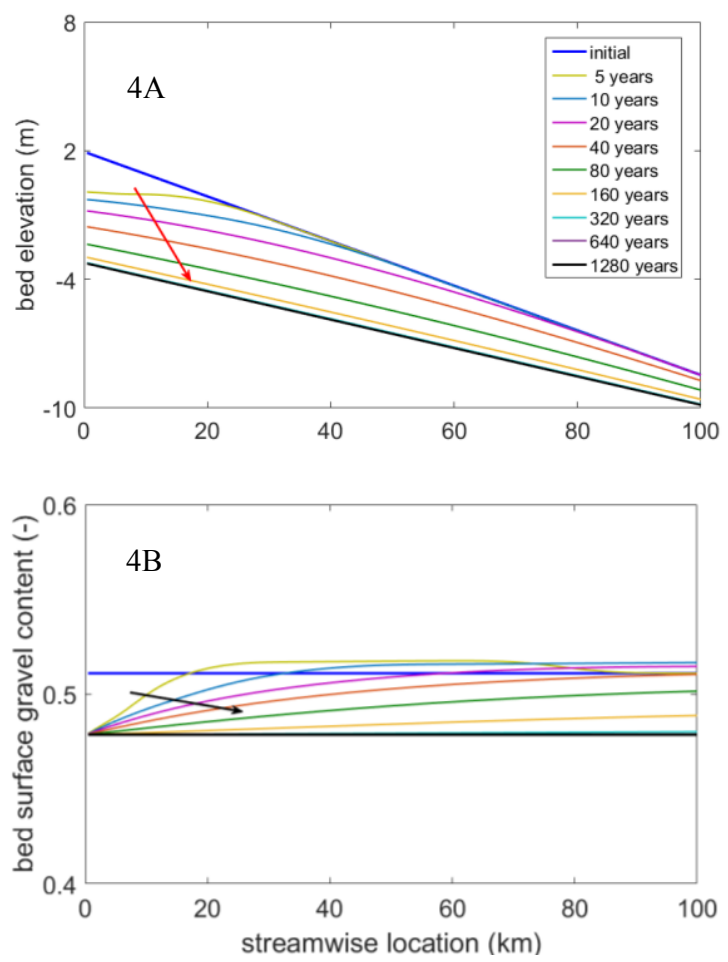

Fig. 4. Channel response to (4A, B) 50\% decrease of the channel width (Case 5). Arrows show the direction of change in the transient phase

\section{Adjustment time scale}

The adjustment time scale indicates the speed at which channel responds to changes in the controls. Here we consider the half-time of bed level change (e.g. [13]) which is the time required to accomplish $50 \%$ of the total bed level change.

We assess the effects of: (a) the type of control, and (b) the magnitude of the perturbation of the controls on the time scale of adjustment. Fig. 5A compares the adjustment time of bed level change for a $10 \%$ and $25 \%$ increase of sand supply and similarly Fig. 5B compares the adjustment time for a $10 \%$ and $25 \%$ of decrease of the channel width. In both cases the upstream reach adjusts faster than the dowstream reach, that is the adjsutment time scale increases with streamwise position, as the disturbance requires time to migrate downstream. Moreover, the sediment volume required to allow for the channel response increases in the downstream direction.

In the case of a change in sand content of the sediment supply, a $25 \%$ increase of sand content is associated with a longer adjustment time than $10 \%$ increase of sand (Fig. 5A). Here a large change in the controls means that a larger volume of sediment is required to be evacuated for equilibration or regrading.

In the case of channel narrowing though, the adjustment time is inversely related with the extent of narrowing (Fig. 5B). A 10\% narrowing is associated with a longer adjustment time than a $25 \%$ decrease of channel width. The equilibrium slope for the latter case is smaller than the former and hence requires evacuation of a larger volume of sediment to 
attain the new equilibrium state. Despite of this, the narrower channel leads to a higher sediment transport capacity, and hence a faster regrading.
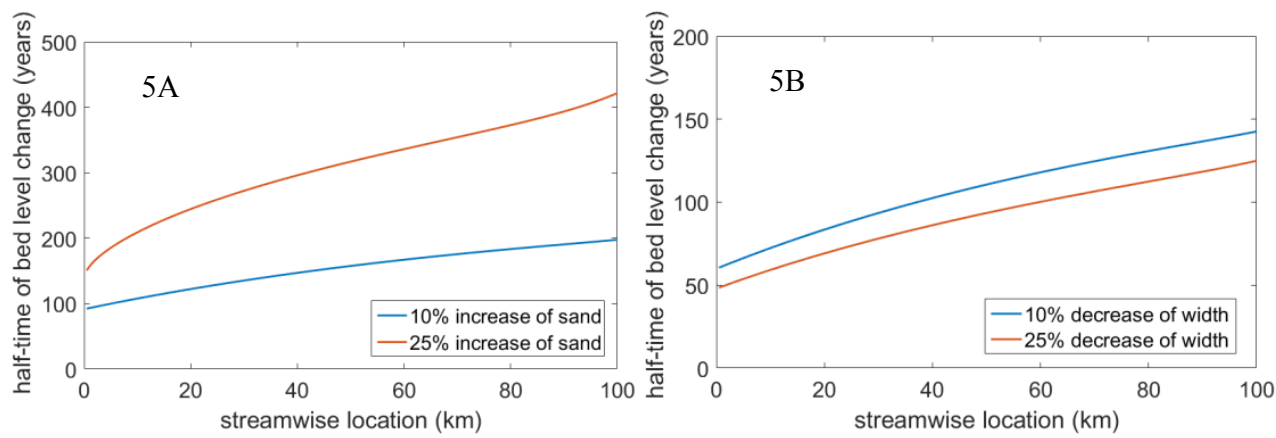

Fig. 5. Half-time of bed level change for (5A) $10 \%$ and $25 \%$ increase of the sand content of the sediment supply (Case 3); and (5B) 10\% and 25\% decrease of channel width, B (Case 5)

\section{Implications to the Dutch Rhine}

The ongoing bed degradation in the Rhine River has several human and natural causes operating at various time and space scales [1] and hence isolating the effect of a single cause is difficult. Yet, our simplified numerical runs provide plenty of insights on the various causes of bed degradation and the associated adjustment time scales. The most important cause is the $19^{\text {th }}-20^{\text {th }}$ century river training works implemented in the Dutch Rhine to improve navigation and reduce flood risk. The river training led to a narrower and shorter river which consequently leads to an increase in sediment capacity. In schematic river reach in Case 5, large scale narrowing leads to a smaller equilibrium slope and thus the transient state is characterized by tilting of the channel towards the new equilibrium slope (Fig. 4A). This slope reduction through channel tilting is the main mechanism of adjustment of the Bovenrijn-Waal River (see Fig. 1 of Blom [1]) and resulted in degradation further upstream, i.e. Bovenrijn and Bovernwaal (Fig. 1). The characteristic time scale of this adjustment process depends on the length scale of the river and the sediment transport and for the Dutch Rhine branches the adjustment can last for several centuries [13]. Other cause of bed degradation include past extensive removal dredging carried out to provide gravel, sand and clay for building construction material. Since 1992 removal dredging has been substituted by re-allocation dredging (dredging and dumping).

\section{Conclusions}

We present and discuss the results of simplified numerical runs to assess the equilibrium state and transient degradational response of engineered channels to changes in the upstream controls and channel width. Five perturbations leading to degradation of an initially equilibrium state are considered: an increase of the water discharge, a decrease of the sediment supply, an increase of the sand content of the sediment supply, an increase of the gravel content of the sediment supply, and a decrease of channel width. The initial and final equilibrium states (regarding bed slope and bed surface texture) are verified against the results of the analytical model by Blom et al [3]. The new equilibrium state determines the transient response of an initially equilibrium channel. The adjustment time depends on the type of control that induces change to the initial equilibrium state and the magnitude of 
the disturbance. Finally, the simplified numerical runs provide insight to assess the cause of long-term bed degradation in engineered rivers, such as the Rhine River.

This research is part of WATER2015 project 'Long-term bed degradation in rivers: causes and mitigation' and is funded by the Netherlands Organization for Scientific Research (NWO), under grant No 14508 .

\section{References}

1. A. Blom, WaterViewer, available at http://waterviewer.tudelft.nl/\#/bed-degradation-inthe-rhine-river-1479821439344 47 (2016)

2. A. Blom, E. Viparelli, V. Chavarrías, Geophys. Res. Lett. 43, 6285-6293 (2016).

3. A. Blom, L. Arkesteijn, V. Chavarrías, E. Viparelli, J. Geophys. Res.: Earth Surf. 122, 1924-1948 (2017)

4. A. Blom, V. Chavarrías, R.I. Ferguson, E. Viparelli, J. Geophys. Res. Lett., 44, 97519760 (2017)

5. A. D. Howard, Earth Surf. Process. and Landf. 7, 303-325 (1982)

6. B. Spinewine, Y. Zech, J. Flood Risk Management 1, 57-68 (2008)

7. E. Meyer-Peter, and R. Müller (1948), Proc. $2^{\text {nd }}$ Meeting Int. Assoc. Hydraul. Struct. Res., 39-64 (1948)

8. G. Parker, P. C. Klingeman, Water Resour. Res. 18, 1409-1423 (1982)

9. H. Miwa, G. Parker, Earth Surf. Process. and Landf. 42, 1355-1364 (2017).

10. I. V. Egiazaroff, J. Hydraul. Div. Am. Soc. Civ. Eng., 91, 225-247(1965).

11. J. C. Curran, P. R. Wilcock, J. of Hydraul. Eng. 131, 961-967 (2005).

12. J. H. Mackin, Geol. Soc. of Am. Bull. 59, 463-512 (1948).

13. M. de Vries, XVIth IAHR Congress, São Paulo, (1975).

14. M. Hirano, Trans. Jpn. Soc. Civ. Eng. 3, 194-195 (1971).

15. R. M. Frings, R.Döring, C. Beckhausen, H. Schüttrumpf, S. Vollmer, J. Catena 122, 91-102 (2014).

16. T. E. Lisle, F. Iseya, H. Ikeda, Water Resour. Res. 29, 3623-3629 (1993).

17. W. E. Dietrich, J. W. Kirchner, H. Ikeda, F. Iseya, Nature 340, 215-217(1989). 